\title{
A CASE OF ACUTE MYELOGENOUS LEUKEMIA IN AN INFANT *
}

J. H. MASON KNOX, JR., M.D.

Associate in Clinical Pediatrics, Johns Hopkins University

BALTIMORE

The case here reported as being of unusual interest is that of a girl, infant L. F., Hebrew, nine months of age, who was admitted to the Thomas Wilson Sanitarium, July 11, 1913.

Family History.-The father and mother were both well, aged 36 and 33 years, respectively. They had lost four other children in infancy, one from scarlet fever and three from "summer complaint." The patient was the only living child. There was no history of syphilis or of tuberculosis. The parents were apparently in comfortable circumstances and the hygienic condition of their home was described as "good."

Past History.-The patient's birth was normal, weight $71 / 2$ pounds. She was exclusively breast fed for six months, and for the last three months a whole milk mixture had been used as a supplementary feeding. The patient had never been ill before and had gained steadily.

Present Illness.-The baby is said to have "caught cold" two weeks previously. She was better, however, and the acute symptoms of the present condition began suddenly and without prodromata only five days before admission. These symptoms consisted principally of nausea and vomiting almost immediately after taking food, with frequent wretchings between feedings. Shortly after the onset diarrhea of moderate severity began, the stools being described as fecal, fluid and mucus, but with no blood, five to eight in twentyfour hours. There was moderate continuous fever and a cough that had persisted for two weeks.

Physical Examination.-This was unimportant for the most part. Patient was fairly well nourished, somewhat pale and exceedingly fretful, weight $153 / 1 \mathrm{~b}$ pounds. The throat was clear and the lungs were negative excepting for a few moist scattered râles. The heart sounds were clear. The abdomen was soft, very slightly diffusely tender and there was no enlargement of spleen. The edge of the liver was palpable. There was no general glandular enlargement; the reflexes were active and the skin clear. The temperature on admission was $102 \mathrm{~F}$. The most prominent symptom during observation was almost constant nausea and vomiting after taking food; it was not forceful in character. Wretching persisted if the patient was aroused during starvation, after breast milk as well as after various cows' milk and cereal mixtures. The temperature remained continuously above $100 \mathrm{~F}$., and in the last four or five days frequently reached $103 \mathrm{~F}$., and once $105 \mathrm{~F}$. The von Pirquet reaction was negative. The ear drums were smooth and glistening. The vomiting continued to be the dominating symptom. The stools were fecal in character and not more than three to five in twenty-four hours. The child lost continually in weight, was irritable when disturbed but not stuporous. There was little change in her condition for ten days. At that time her condition became decidedly more

* Read at the Twenty-Seventh Session of the American Pediatric Society, Lakewood, N. J., May, 1915. 
serious. The vomitus developed a fecal odor. The stools at this time were four in twenty-four hours, and fecal in character. There were no other symptoms suggesting intestinal obstruction. The patient became progressively worse. A leukocyte count made at this time showed a great increase in white cells, which numbered nearly 200,000 per cubic millimeter. Smears were made, but were not studied for several days. The patient, twelve days after admission had a number of convulsive seizures ending in coma and death. Necropsy was refused.

The exciting cause of the vomiting was not determined during life. The symptoms seemed to point to gastro-intestinal intoxication with unusual gastric irritability. The differential count of the leukocytes showed the presence of a large number of myelocytes from the bone marrow and suggested the diagnosis of acute myelogenous leukemia.

The report of Dr. W. A. Baetjer of the Clinical Laboratory of the Johns Hopkins Hospital, to whom the specimen was referred, is as follows:

Leukocytes 200,000; differential count, Wilson stain, 500 cells:

$$
\begin{aligned}
& \text { Per } \\
& \text { Cent. } \\
& \text { Polymorphonuclear neutrophils... } 47 . \\
& \text { Polymorphonuclear basophils.... } 0 \text {. } \\
& \text { Large mononuclears............. } 0 .
\end{aligned}
$$$$
\text { Polymorphonuclear eosinophils... } 4.2
$$$$
\text { Lymphocytes ................. } 28.6
$$$$
\text { Transitionals .................... } 0 \text {. }
$$

Blood Picturc.-Moderate secondary anemia; no marked reduction in number of red blood cells; very few nucleated reds. Platelets about normal; no striking fragility of the cells. Polymorphonuclear neutrophils young, often with scanty granulations. The lymphocytes are mostly of the typical small variety; there are, however, a fair number of larger forms with deep basic protoplasm.

Picture resembles chronic myeloid leukemia, except for the predominance of atypical granulations in most of the myelocytes and in the high percentage of small lymphocytes, probably due to the age of the patient (9 months).

Diagnosis.-Acute myeloid leukemia; type, clinically acute. Blood picture resembling chronic myeloid leukemia with high percentage of lymphocytes due to age.

It is not the object of this report to enter upon any discussion of myeloid leukemia as a pathologic process, but simply to place this case on record as the youngest case we have been able to find in which the blood picture was characteristic. The youngest patient in a series of sixty cases of myeloid leukemia reported by Naegoli was four years.

Besides the extreme youth of the patient, the rapid course of the disease, less than three weeks, is noteworthy. There was no enlargement of the lymphatic glands or of the spleen and no evidence of hemorrhage or of necrosis of the mucous membranes. The symptoms apparently were referable to the gastro-intestinal tract. The great number of leukocytes in the circulating blood, 200,000 per c.mm. was too many to be accounted for by a possible focus of infection and directed attention to a further study of the blood. While it is possible to have perhaps as high as 15 per cent. of myelocytes in acute infections, these cells are of the typically neutrophilic variety. In this case, 
however, the atypical granulations seen in the neutrophilic myelocytes, as well as the presence of eosinophilic and basophilic varieties, is good evidence of primary disease of the blood-forming organs.

From the standpoint of diagnosis, this case is of value, in that it indicates that an examination of the blood may shed light in certain instances, in infancy, of excessive nausea and vomiting, not otherwise explained. 